\title{
Demographic Profile of Liver Injury Managed at a Tertiary Care Hospital in Central Nepal -A Retrospective Study
}

\author{
Narayan Prasad Belbase, ${ }^{1}$ Aditya Kumar Jalan, ${ }^{1}$ Hari Upadhyay, ${ }^{2}$ Rohit Mishra, ${ }^{1}$ Mukesh Karki, \\ Sujit Kumar ${ }^{1}$ \\ ${ }^{1}$ Department of Surgical Gastroenterology, ${ }^{2}$ Department of Community Medicine, College of Medical \\ Sciences, Bharatpur, Chitwan.
}

\section{Correspondence}

Dr. Narayan Belbase,

Department of Surgical

Gastroenterology, College of

Medical Sciences, Bharatpur,

Chitwan

Email:

narayan_299@yahoo.co.nz

DOI: http://dx.doi.org/10.3126/ jemsn.v14i1.18884

Orcid ID: orcid.org/0000-0002 $-8380-165 \mathrm{X}$

Article received: Jan $2^{\text {nd }} 2018$

Article accepted: Feb $11^{\text {th }} 2018$

\begin{abstract}
Background \& Objectives: The liver is one of the commonly injured solid organ following abdominal trauma. The aim of this study was to determine the outcome of liver injuries managed operatively or nonoperatively and predict factors affecting morbidity and mortality. Materials \& Methods: This was a retrospective study of 40 liver injuries managed in the department of Surgical Gastroenterology at College of Medical Sciences over a period of 2 years. The liver injury was classified in accordance with the American Association for the Surgery of Trauma liver injury scoring scale. Patients were divided into two groups those managed operatively or non-operatively and were compared in terms of demographic profile and outcome. Results: Forty patients were analyzed. The mean age of the patients was 29.95years. Male predominance was seen with $72.5 \%$ of the cases. Road traffic accidents were the commonest mode of injury seen in $72.5 \%$ cases. The mean Revised Trauma Score (RTS) and Injury severity score (ISS) were 7.11 and 22.58. The mean systolic BP, hospital stay and ICU stay were $93.80 \mathrm{~mm}$ of mercury, 11.55 days and 3.55 days respectively. Twenty six patients $(65 \%)$ were initially managed non-operatively and 14 patients were managed operatively. Five patients had to be converted to operative management for hemodynamic instability. Mortality was $7.6 \%$ in patient undergoing nonoperative management and $21.43 \%$ in patients managed operatively. Low systolic BP at presentation, low RTS score, high ISS score, high AST, ALT and prothrombin time were significantly associated with operative management and mortality. Conclusion: Patients with hemodynamic instability, low RTS score, high ISS score, high liver enzymes have high likelihood of operative management.
\end{abstract}

Key words: Liver injury; non-operative management; operative management.

Citation: Belbase NP, Jalan AK, Upadhya H, Mishra R, Karki M, Kumar S. Demographic Profile of Liver Injury Managed at a Tertiary Care Hospital in Central Nepal -A Retrospective Study. JCMS Nepal. 2018;14 (1):32-8.

\section{INTRODUCTION}

Helical computerized tomography, has helped to classify the extent of liver injury and has eased the selective, non-operative management (NOM) of patients with blunt abdominal trauma. However, a number of patients either due to the severity of their liver injury or associated intra-abdominal injuries, do require operative management $(\mathrm{OM}){ }^{1}{ }^{1}$ The management of blunt abdominal trauma is challenging. Currently, conservative treatment is the gold standard for solid organ injuries in haemodynamically stable patients whereas hollow organs injury requires surgery. ${ }^{2}$ Besides the advantage of avoiding morbidity from a laparotomy, non-operative treatment of hepatic trauma has shown a reduction in the need for blood transfusions, a lower rate of abdominal complications, a shorter length of hospital stay and lower mortality. ${ }^{3}$

This study aims to examine the outcomes of blunt hepatic trauma, and compare factors predicting 
successful non-operative and operative outcomes in patients in a tertiary care hospital of central Nepal.

\section{MATERIALS AND METHODS}

This is a retrospective study conducted in the department of Surgical Gastroenterology at College of Medical Sciences and Teaching Hospital (COMS $-\mathrm{TH})$, Bharatpur, a tertiary care and referral center in central Nepal. Record files of all the patients with abdominal trauma with liver injury managed at COMS-TH over a period of two years $\left(1^{\text {st }}\right.$ May 2015 to $30^{\text {th }}$ April 2017) were evaluated. Patients who had been operated in a different hospital and those who had GCS less than 8 following concomitant head injury were excluded. Included in the study were: demographic variables, age, gender, systolic BP at presentation, time delay to reach hospital, mode of injury, presence or absence of shock, number of units of blood transfused, liver function test, Ultrasonography (USG) and Contrast enhanced computerized tomography (CECT) findings, Revised Trauma Score (RTS), Injury Severity Score (ISS), intra-operative findings, associated intra-abdominal injuries, mode of surgical management, hospital and ICU stay, complications of management. The liver injury was classified using the organ injury scale (OIS) of the American Association for the Surgery of Trauma (AAST).

Patients presenting in shock were resuscitated using crystalloid and blood as needed. Patients who responded to fluid challenge were subjected to CECT abdomen and liver injury was graded. Patients with CT scan suggestive of active bleed were taken for laparotomy and CT scan showing grade III and below without active bleed were subjected for non-operative management. Patients not responding to fluid challenge and those with USG showing gross hemoperitoneum with liver injury with or without peritonitis were directly taken for laparotomy.

If the patient became unstable or developed signs of peritoneal irritation, it was considered a failure of the non-operative treatment and an exploratory laparotomy was performed.

Data were entered directly into SPSS version 20 and were analyzed. Their frequencies, mean, standard deviation were calculated. Means of groups were calculated using Chi-square, independent sample t-test and ANOVA test. Stastical significance was considered if $\mathrm{p}$-value was less than 0.05 .

\section{RESULTS}

During the period of two years, forty-eight patients were admitted with the diagnosis of liver injury. Three patients had undergone laparotomy in other institutions and were referred to us. Four patients with liver injury and concomitant head injury with GCS less than 8 were excluded. One patient was referred to Kathmandu on their request.

Forty patients were analyzed. The mean age of the patients was $29.95+/-16.43$ years (minimum age was 2 years and maximum was 78 years) and male predominance was seen with $72.5 \%$ of the cases. Road traffic accidents were the commonest mode of injury seen in $72.5 \%$ cases followed by fall from height in $20 \%$ cases, physical assault in $5 \%$ and penetrating injury in $2.5 \%$ cases. The mean RTS and ISS score were $7.11+/-1.091$ and $22.58+/$ 10.042.The mean systolic BP, hospital stay and ICU stay were $93.80+/-18.92 \mathrm{~mm}$ of mercury, $11.55+/-5.65$ days and $3.55+/-2.03$ days respectively. Coming to grades of liver injury grade III injury was the most common injury seen in $37.5 \%$ cases followed by grade II injury in $35 \%$, grade IV injury in $22.5 \%$, grade I in $2.5 \%$ and grade $\mathrm{V}$ in $2.5 \%$ cases.

Twenty six patients $(65 \%)$ were initially managed non-operatively and $14(35 \%)$ patients were managed operatively. Five patients had to be converted to operative management. Persistent ileus and delayed laparotomy were seen in $19.62 \%$ of the patients undergoing non-operative management. Mortality was $7.6 \%$ in patient managed nonoperatively and $21.43 \%$ in patients managed operatively. The cause of death in non-operative management was delayed laparotomy with sepsis with MODS. Among death in operative management one death was intra-operatively due to massive liver injury (grade V) with IVC injury with irreversible shock, second death was in a patient with right hepatectomy who developed Myocardial infarction on 5th post-operative day and the third death was following ventilator associated pneumonia with sepsis with MODS. Among patients managed operatively surgical site infection was seen in $36.84 \%$ cases, persistent bile leak in $26.5 \%$ cases, death in $26.3 \%$ (three deaths were from patients managed operatively initially and two deaths from converted patients) cases and ventilator associated pneumonia in $10.52 \%$ cases. Out of five patients with bile leak two cases closed spontaneously and three cases were referred for ERCP stenting. 
Table 1. Parameters comparing non-operative and operative management.

\begin{tabular}{|c|c|c|c|}
\hline Parameters & Management & Mean & p-value \\
\hline \multirow{2}{*}{ Age } & Non-operative & $29.53+/-18.56$ years & \multirow{2}{*}{0.832} \\
\hline & Operative & $30.71+/-12.10$ years & \\
\hline \multirow{2}{*}{ Systolic BP } & Non-operative & $96.76+/-18.57 \mathrm{mmHg}$ & \multirow{2}{*}{0.184} \\
\hline & Operative & $88.28+/-19.00 \mathrm{mmHg}$ & \\
\hline \multirow{2}{*}{ RTS } & Non-operative & $7.31+/-0.83$ & \multirow{2}{*}{0.112} \\
\hline & Operative & $6.73+/-1.41$ & \\
\hline \multirow{2}{*}{ ISS } & Non-operative & $19.42+/-8.40$ & \multirow{2}{*}{0.014} \\
\hline & Operative & $29.57+/-9.73$ & \\
\hline \multirow{2}{*}{ ALT } & Non-operative & $486.88+/-447.60 \mathrm{IU} / \mathrm{L}$ & \multirow{2}{*}{0.001} \\
\hline & Operative & 1189.5+/-788.11 IU/L & \\
\hline \multirow{2}{*}{ AST } & Non-operative & $607.07+/-785.52 \mathrm{IU} / \mathrm{L}$ & \multirow{2}{*}{0.004} \\
\hline & Operative & $1562.14+/-1197.28 \mathrm{IU} / \mathrm{L}$ & \\
\hline \multirow{2}{*}{ PT } & Non-operative & $15.91+/-2.20 \mathrm{secs}$ & \multirow{2}{*}{0.006} \\
\hline & Operative & $18.1+/-2.32 \mathrm{secs}$ & \\
\hline \multirow{2}{*}{ Platelets } & Non-operative & $182200+/-69181.7$ & \multirow{2}{*}{0.309} \\
\hline & Operative & $160500+/-50711.47$ & \\
\hline \multirow{2}{*}{ Hospital stay } & Non-operative & $11.42+/-6.04$ & \multirow{2}{*}{0.84} \\
\hline & Operative & $11.79+/-5.05$ & \\
\hline \multirow{2}{*}{ ICU stay } & Non-operative & $3.19+/-2.26$ & \multirow{2}{*}{0.13} \\
\hline & Operative & $4.21+/-1.36$ & \\
\hline \multirow{2}{*}{ Blood transfused } & Non-operative & $2.15+/-1.89$ & \multirow{2}{*}{0.002} \\
\hline & Operative & $4.93+/-2.56$ & \\
\hline
\end{tabular}

Table 2. Operative procedures $(n=19)$.

\begin{tabular}{|c|c|c|}
\hline Procedures & Frequency & Percentage \\
\hline Peritoneal lavage and perihepatic packing only & 5 & 26.32 \\
\hline Anatomical/non-anatomical liver resection with cholecystectomy & 5 & 26.32 \\
\hline Hepatorrhaphy with cholecystectomy & 1 & 5.26 \\
\hline Right hepatectomy & 1 & 5.26 \\
\hline Non-anatomical resection of liver segments & 1 & 5.26 \\
\hline Suture hepatorrhaphy with omenta buttressing & 1 & 5.26 \\
\hline Suture hepatorrhaphy with repair of diaphragmatic injury & 1 & 5.26 \\
\hline $\begin{array}{l}\text { Hepatorrhaphy with splenectomy with or without resection } \\
\text { anastomosis of bowel }\end{array}$ & 2 & 10.52 \\
\hline $\begin{array}{l}\text { Right hepatectomy with cholecystectomy with CBD repair over T- } \\
\text { Tube }\end{array}$ & 1 & 5.26 \\
\hline Right hepatectomy with Repair of IVC & 1 & 5.26 \\
\hline
\end{tabular}


Table 3. Associated intra-abdominal injuries.

\begin{tabular}{|c|c|c|}
\hline Injuries & Frequency & $\%$ \\
\hline Gallbladder perforation & 6 & 31.57 \\
\hline $\begin{array}{l}\text { Zone } 1 \text { retroperitoneal } \\
\text { hematoma }\end{array}$ & 3 & 15.78 \\
\hline Splenic injuries & 3 & 15.78 \\
\hline CBD injury & 1 & 5.26 \\
\hline Pancreatic Injury II & 1 & 5.26 \\
\hline $\begin{array}{l}\text { IVC injury with } \\
\text { retroperitoneal } \\
\text { hematoma }\end{array}$ & 1 & 5.26 \\
\hline Diaphragmatic injury & 1 & 5.26 \\
\hline
\end{tabular}

Patients undergoing operative management had higher grades of liver injury and more blood transfused (p-value 0.013 and 0.004 respectively).

Tables 1,2,3,4 and 5 show the different parameters compared between operative and non-operative management, different operative procedures performed, associated intra-abdominal injuries, factors predicting failure of non-operative management and factors predicting mortality respectively. There was no significant difference in age of patients, systolic BP at presentation, RSS score and platelets $(\mathrm{p}>0.05)$ but ISS score, AST, ALT and PT was significantly higher $(p<0.05)$ in the operative group than in the non-operative group.

Table 4. Factors predicting failure of non-operative management (NOM).

\begin{tabular}{lllc} 
Parameters & Management & Mean & p-value \\
Age & Successful NOM & $27.71 \pm 15.70$ & 0.311 \\
& Failed NOM & $37.20 \pm 28.630$ & \\
Systolic BP & Successful NOM & $101.71 \pm 15.86$ & 0.003 \\
FTS & Failed NOM & $76.00 \pm-15.166$ & \\
& Successful NOM & $7.53 \pm 0.63$ & 0.003 \\
ISS & Failed NOM & $6.36 \pm 0.96$ & \multirow{2}{*}{0.015} \\
& Successful NOM & $17.52 \pm 7.90$ & \\
ALT & Failed NOM & $27.40 \pm 5.50$ & 0.001 \\
& Successful NOM & $323.48 \pm 214.53$ & \multirow{2}{*}{0.001} \\
AST & Failed NOM & $1173.20 \pm 541.36$ & \\
& Successful NOM & $302.24 \pm 240.56$ & 0.02 \\
PT & Failed NOM & $1187.40 \pm 1015.03$ & \\
& Successful NOM & $15.30 \pm 1.80$ & 0.32 \\
Platelets & Failed NOM & $18.48 \pm 1.99$ & \\
& Successful NOM & $188914.29 \pm 68390.01$ & \\
\hline
\end{tabular}

Peritoneal lavage and perihepatic packing only $(26.32 \%)$ and anatomical/non-anatomical liver resection with cholecystectomy $(26.32 \%)$ were the most common procedures performed. Gallbladder perforation $(31.57 \%)$, zone I retroperitoneal hematoma $(15.78 \%)$ and splenic injuries $(15.78 \%)$ were the common intra-abdominal injuries associated with liver injuries found at laparotomy. Low systolic BP, low RTS score, high ISS score, high AST, ALT and high prothrombin time were predictors of failure of non-operative management and mortality and these findings were significant with $\mathrm{p}$ value $<0.05$.

\section{DISCUSSION}

Hepatic injury is a common but serious consequence of blunt abdominal trauma. The primary focus of trauma surgeons was to find out the most appropriate technique in patients with hepatic injuries. The literature now reports over $80 \%$ of blunt hepatic injuries can be managed with NOM. It has been reported as safe and effective regardless of the grade of hepatic trauma. ${ }^{4}$

A high percentage of liver injuries, around $85 \%$ are not severe $(<$ grade IV), which previously were treated with electrocoagulation, topical hemostatic agents or superficial ligature. During laparotomy of 
Table 5. Factors predicting mortality in liver trauma.

\begin{tabular}{|c|c|c|c|}
\hline Parameters & Management & Mean & p-value \\
\hline \multirow[t]{2}{*}{ Age } & No mortality & $28.43+/ \_14.60$ & 0.315 \\
\hline & Mortality & $40.60+/ 25.64$ & \\
\hline \multirow[t]{2}{*}{ Systolic BP } & No mortality & $97.49+/ 17.05$ & 0.001 \\
\hline & Mortality & $68.0+/ 8.36$ & \\
\hline \multirow[t]{2}{*}{ RTS } & No mortality & 7.39+/_0.78 & 0.000 \\
\hline & Mortality & $5.09+/ 0.77$ & \\
\hline \multirow[t]{2}{*}{ ISS } & No mortality & $21.09+/ 8.85$ & 0.001 \\
\hline & Mortality & $36.20+/ 8.22$ & \\
\hline \multirow[t]{2}{*}{ ALT } & No mortality & $545.34+/ 397.80$ & 0.000 \\
\hline & Mortality & 2045.00+/_767.22 & \\
\hline \multirow[t]{2}{*}{ AST } & No mortality & $615.71+/ 529.79$ & 0.000 \\
\hline & Mortality & 3220.80+/_884.31 & \\
\hline \multirow[t]{2}{*}{ PT } & No mortality & $16.21+/ 2.13$ & 0.014 \\
\hline & Mortality & $19.96+/ 2.15$ & \\
\hline \multirow[t]{2}{*}{ Platelets } & No mortality & $185462.86+/ 59346.47$ & 0.003 \\
\hline & Mortality & $98600.00+/ 33952.90$ & \\
\hline \multirow[t]{2}{*}{ Blood transfusions } & No mortality & $2.77+/ 2.30$ & 0.078 \\
\hline & Mortality & $5.70+/ 2.70$ & \\
\hline
\end{tabular}

Table 6. Comparison of NOM, OM, failure of NOM and mortality in different studies.

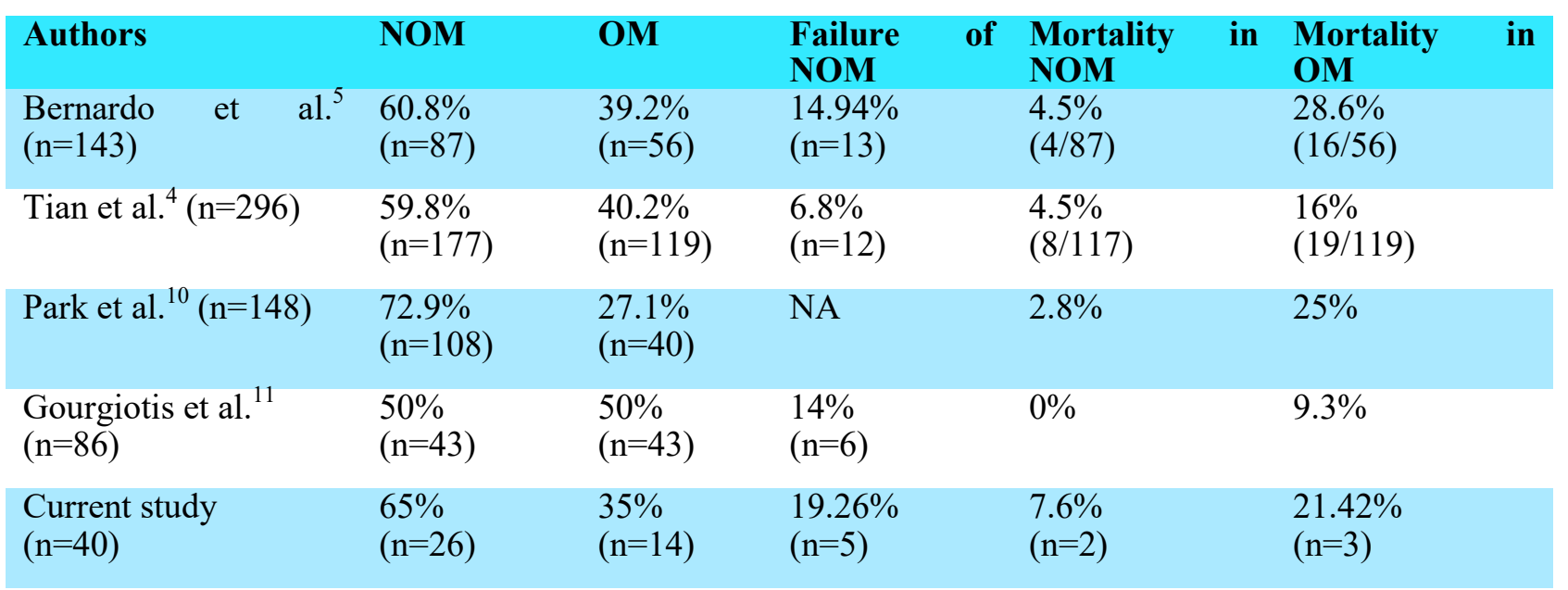

these injuries, the hemorrhage had ceased at the time of surgery in a considerable number of case $(>80 \%$ cases). It is in this group of patients that conservative treatment undoubtedly achieves the greatest percentage of success. However, in the remaining $10-20 \%$ of the severe hepatic injuries the decision as to whether surgery is necessary represents a difficult challenge for the surgeon. ${ }^{5}$ In the series published, the applicability of NOM in patients with liver injury has varied from $35 \%$ to $82 \%$ according to the year, the selection criteria and the number of patients studied. The two main variables guiding the therapeutic approach were hemodynamic instability and the need for transfusion. ${ }^{5}$

In the current study conducted over two years, road traffic accidents were the commonest mode of injury seen in $72.5 \%$. Pachter et al. $^{6}$ and Brammer 
et al. ${ }^{7}$ in their studies found road traffic accidents as the cause of blunt hepatic trauma in $67-72 \%$ cases.

The mean age of the patients was $29.95+/-16.43$ years and male predominance $(72.5 \%)$ was seen in the current study. Similar findings with mean age ranging from 29 years to 35 years and male predominance was seen in studies conducted by Alzahrani et al. ${ }^{8}$ and Malhotra et al. ${ }^{9}$

We found a predominance of grade II $(35 \%)$ and grade III $(37.5 \%)$ liver injuries in our patients. Bernardo et al. ${ }^{5}$ and Pachter et al. ${ }^{6}$ also demonstrated a predominance of grade II $(23 \%$ $31 \%)$ and grade III (36\%-39\%) liver injuries in their studies.

The mean RTS and ISS score at admission were $7.11+/-1.091$ and $22.58+/-10.042$ and these findings were similar to the mean RTS and ISS score in a study conducted by Morales Uribe et al. ${ }^{1} 7.55$ and 22.0 respectively.

In the present study $65 \%$ patients were initially managed non-operatively and 35\% patients were managed operatively. Five patients (19.26\%) patients from NOM had to be converted to OM. The reason for conversion was development of peritonitis in three patients and falling hemoglobin in two patients. There was $7.6 \%$ mortality in the NOM group and $21.42 \%$ in the OM group. These findings are comparable to the findings as shown in the Table 6. The failure of NOM and mortality in NOM was higher in our case because we could not use adjunctive methods like angioembolization or percutaneous drainage techniques and also the sample size was small than the other studies.

Perihepatic packing, hepatorrhaphy, and anatomical/non-anatomical resection were the common procedures performed in the current study. Similar operative interventions were seen in the study conducted by Hussain et al. ${ }^{12}$ and Tian et al. ${ }^{4}$ In the current study low RTS score, high ISS score, low systolic BP, high AST and ALT, high PT where predictors of failure of nonoperative management and mortality $(\mathrm{p}<0.05)$. Zago et al. ${ }^{3}$ in their study found low mean systolic BP, low RTS score, high ISS score, more blood transfusions and high grade liver injury to be predictors of failure of nonoperative management and mortality. Also Morales Uribe et al. ${ }^{1}$ in their study found low RTS score, high ISS score, low systolic BP at presentation to be predictors of failure of nonoperative management and mortality.

\section{CONCLUSION}

From the current retrospective study it can be concluded that nonoperative management of liver injury is feasible in most of the blunt liver injury provided the patient is hemodynamically stable and bowel injury is ruled out. Patient with low RTS score, high ISS score, low systolic BP at presentation, high AST, ALT level and high PT have high probability of operative management, failure of nonoperative management and high predictability of mortality.

Limitations: Small sample size, short study period and lack of adjunctive modalities like provision of angioembolization and ERCP facility were the limitations of this study.

Acknowledgements: To all those patients who gave the opportunity for the conduct of this study.

\section{Funding}

None

Conflict of Interest Statement:

None Declared

\section{REFERENCES}

1. Morales Uribe $\mathrm{CH}$, Lopez CA, Cote JC, Franco ST, Saldarriaga MF, Mosquera J, et al. Surgical treatment of blunt liver trauma, indications for surgery and results. Cir Esp. 2014; 92(1):23-9. https://doi.org/10.1016/ j.ciresp.2013.08.001. PMID: 24176191.

2. Pimentel SK, Sawczyn GV, Mazepa MM, da Rosa FG, Nars A, Collaco IA. Risk factors for mortality in blunt abdominal trauma with surgical approach. Rev Col Bras Cir. 2015; 42(4):259-64. https://doi.org/10.1590/010069912015004011. PMID: 26517802.

3. Zago TM, Pereira BM, Calderan TR, Hirano ES, Rizoli S, Fraga GP. Blunt hepatic trauma: comparison between surgical and nonoperative treatment. Rev Col Bras Cir. 2012;39(4):307-13. 69912012000400011 https://doi.org/10.1590/S0100-

4. Tian ZQ, Su XF, Yu F, Liu H, Fang Z, Luo KL. A 10-year experience with hepatic trauma in a Chinese level one trauma center. Saudi Med J. 2014;35(9):1150-3. PMID: 25228195.

5. Bernardo CG, Fuster J, Bombuy E, Sanchez S, Ferrer J, Loera MA, et al. Treatment of liver trauma: operative or conservative management. Gastroenterology Res. 2010;3 (1):9-18. https://doi.org/10.4021/gr2010.02.165w.

6. Pachter HL, Knudson MM, Esrig B, Ross S, Hoyt D, Cogbill T, et al. Status of nonoperative management of blunt hepatic injuries in 1995: a multicenter experience with 404 patients. J Trauma. 1996;40(1):31-8. https:// doi.org/10.1097/00005373-199601000-00007. PMID: 8576995 .

7. Brammer RD, Bramhall SR, Mirza DF, Mayer AD, McMaster P, Buckels JA. A 10-year experience of complex liver trauma. Br J Surg. 2002;89(12):1532-7. https:// doi.org/10.1046/j.1365-2168.2002.02272.x. PMID: 12445061.

8. Alzahrani OA, Alzahrani F, Alghamdi M, Alnemary M, Alrahman A. Non-operative management of liver injury among abdominal trauma patients admitted to Al-Noor specialist hospital in Makkah Al-Mukarmah: a retrospective cohort study, 2013 - 2014. Int J Med Res 
Prof. 2017;3(5):225-8.

9. Malhotra AK, Fabian TC, Croce MA, Gavin TJ, Kudsk KA, Minard G, et al. Blunt hepatic injury: a paradigm shift from operative to nonoperative management in the $1990 \mathrm{~s}$ Ann Surg. 2000; 231(6):804-13. https:// doi.org/10.1097/00000658-200006000-00004. PMID 10816623.

10. Park KB, You DD, Hong TH, Heo JM, Won YS Comparison between operative versus non-operative management of traumatic liver injury. Korean J Hepatobiliary Pancreat Surg. 2015; 19(3):103-8. https:// doi.org/10.14701/kjhbps.2015.19.3.103. PMID: 26379731.

11. Gourgiotis S, Vougas V, Germanos S, Dimopoulos N, Bolanis I, Drakopoulos S, et al. Operative and nonoperative management of blunt hepatic trauma in adults: a singlecenter report. J Hepatobiliary Pancreat Surg. 2007;14 (4):387-91. https://doi.org/10.1007/s00534-006-1177-2. PMID: 17653638.

12. Hussain MI, Alam MK, Al-Akeely MH, Mohammed AA. Operative management of liver trauma. A 10-year experience in Riyadh, Saudi Arabia. Saudi Med J. 2009;30 (7):942-6. PMID: 19618012. 